\title{
Factors Affecting the Communication Competence in Iranian Nursing Students: A Qualitative Study
}

\author{
Mina Jouzi ${ }^{1}$; Zohreh Vanaki ${ }^{1, *}$; Easa Mohammadi ${ }^{1}$ \\ ${ }^{1}$ Department of Nursing, Faculty of Medical Sciences, Tarbiat Modares University, Tehran, IR Iran \\ *Corresponding Author: Zohreh Vanaki, Department of Nursing, Faculty of Medical Sciences, Tarbiat Modares University, Tehran, IR Iran. Tel: +98-2182883814, E-mail: vanaki_z@ \\ modares.ac.ir
}

Received: April 23, 2014; Revised: May 27, 2014; Accepted: July 3, 2014

\begin{abstract}
Background: Communication competence in nursing students is one of the nursing education requirements, especially during the internship period, the final stage of the bachelor nursing education in Iran. Several factors can influence this competence and identifying them could help provide safe care by nursing students in the future.

Objectives: This study aimed to investigate factors that influence nursing students' communication competence.

Patients and Methods: A purposeful sampling technique was used to select 18 nursing students who had completed their internship. Semi-structured interviews were conducted and data were analyzed by the conventional qualitative content analysis method.

Results: After data analysis, three main categories were achieved: organizational factors, humanistic factors and socio-cultural factors. The main and latent theme that affected the students' communication competence was not being accepted as a caregiver in the clinical environment.

Conclusions: With regards to students not being accepted in health care environments, it is recommended to plan special programs for empowering students to acquire better social state and acceptance by the health care team.
\end{abstract}

Keywords:Competence; Nursing Student; Education; Research, Qualitative

\section{Background}

Competency as the outcome of an educational system is a complex concept, encompassing different areas of learning (1). Nursing competency covers a wide range of knowledge, performance and ability in various fields (2). Nursing care environments need a nurse who is able to work independently at a competent level; however, administrators are concerned about the performance of newly graduated nurses. Therefore, the competency of students is approved by the education system when they are about to graduate (3). This is the internship period in Iran, which is during the fourth year of bachelor of nursing. During this period, students pass all clinical courses again and then they can enter clinical environments as newly graduated nurses. Complete achievement of professional competencies is the outcome of a good education system yet unfortunately according to conducted researches, the achievement of professional competencies by students is not enough $(1,4)$. One of the basic components of clinical competency is how to communicate with co-workers, managers and patients $(3,5)$. Nurses should have sufficient communication power (6, 7), which affects the patients' experiences during their hospital stay and is associated with patients' satisfaction, anxiety reduction and their recovery $(8,9)$. Acquiring communication skills and interpersonal relation- ships is fundamental for beginners, (10) and is associated with students' professional growth and development (11); therefore newly registered nurses should have effective, multidisciplinary and therapeutic interaction with patients, families, caregivers and other medical team members $(12,13)$. Preparing students to create constructive communicative relationships is essential to nursing practice (14), because it enables students to respect (15) and provide safe nursing care for patients. However some studies show that nursing students do not have the necessary knowledge and skills to communicate with patients (16) and one of the problems of newly graduated nurses is the lack of readiness to communicate with patients and families, that is recognized as a disturbing factor for nurses' clinical performance (17). A review on the topics of the nursing curriculum in Iran showed that communication skills are not considered as a unique syllabus and in some courses only a few hours are dedicated to it. Therefore, it can be claimed that the Iranian nursing students are not able to communicate effectively after graduation and require both educational and clinical support for acquisition of this competence (18). Apart from the lack of theoretical education of this competency in nursing faculties of Iran, other factors can also influence acquisition of communication competence by students, especially 
during the internship period as the final part of education. Considering the unique properties of the internship period in Iran and that the required competencies vary from one place to another (19), it could be accepted that factors affecting Iranian students' communication competence, can also be different. Therefore, in the current study we tried to obtain basic information from different Iranian institutions.

\section{Objectives}

This research aimed to assess factors that affect the communication competence of nursing students in Iran during the period between 2012 and 2014.

\section{Patients and Methods}

This study was a qualitative content analysis. Semistructured interviews were used to collect data. The researchers organized the large amounts of data, made inferences in the data on the basis of the context, provided new insights, and conceptualized realities presented in the text.

\subsection{Participants}

The participants in this study were selected by the purposive sampling method, which is an appropriate method of sampling in qualitative studies (20). In order to create maximum variety in samples and perceive broader dimensions of the subject (maximum variation sampling) the participants from different universities and hospitals were involved in this research. We selected the cases that had excellent experience during their Internship period and had the ability to express their opinions
(21). The inclusion criteria for students was having passed the internship period, and for educators was having experience in internship training, and for nurses was working in educational units in which internship students were trained. Lack of tendency to cooperate, not passing the internship period (for students) and revoking conscious satisfaction, were considered as the exclusion criteria. However nobody refused to participate in this study.

\subsection{Data Collection}

All the interviews were performed by the first author, and recorded on a digital voice recorder. The interviewer was a nursing PhD student and faculty member of the university with sufficient experience in the field of internship, with some studies and publications on this subject. The participants were interviewed face-to-face by the interviewer visiting their hospital or their university, and were coded in chronological order (Table 1). In-depth semi-structured interviews (30-90 minutes) were held for questions requiring open-ended and interpretative answers $(20,21)$. The key question for the students was: "during the internship period, what factors have had the most influence on your communication skills, positively or negatively?" and the instructors' and personnel's question was: "According to your experience, what factors can affect students' communication competence acquisition?" Follow-up questions continued based on the participants' responses. The sampling was continued until there were no new findings and similar matters were becoming repetitive. In other words, interviews were continued to obtain data saturation. Finally, by the $18^{\text {th }}$ interview, we reached data saturation.

\begin{tabular}{|c|c|c|c|c|c|c|}
\hline $\begin{array}{l}\text { Participant's } \\
\text { Code }\end{array}$ & Educational/Work Level & $\begin{array}{l}\text { Work or Edu- } \\
\text { cation City }\end{array}$ & Gender & Age, $y$ & $\begin{array}{l}\text { Work Expe- } \\
\text { rience, } y\end{array}$ & $\begin{array}{l}\text { Work Experience during } \\
\text { the Internship Period, y }\end{array}$ \\
\hline N1 & Head nurse (Bachelor) & Isfahan & Female & 37 & 13 & 13 \\
\hline N2 & Registered nurse (Bachelor) & Isfahan & Female & 32 & 9 & 8 \\
\hline N3 & Registered nurse (Bachelor) & Shahrekord & Female & 35 & 11 & 10 \\
\hline CA1 & Master in nursing (Administrator) & Najafabad & Female & 38 & 13 & 12 \\
\hline I1 & Instructor (master degree) & Ahvaz & Male & 33 & 8 & 8 \\
\hline I2 & Instructor (bachelor degree) & Najafabad & Female & 35 & 5 & 2 \\
\hline I3 & Instructor (master degree) & Babol & Female & 37 & 12 & 8 \\
\hline 14 & Instructor (master degree) & Booshehr & Male & 40 & 13 & 13 \\
\hline I5 & Instructor (master degree) & Tehran & Female & 36 & 11 & 9 \\
\hline S1 & Bachelor of nursing student & Isfahan & Female & 22 & & \\
\hline S2 & Bachelor of nursing student & Najafabad & Female & 23 & & \\
\hline S3 & Master of nursing student & Laar & Male & 24 & & \\
\hline S4 & Master of nursing student & Babol & Female & 23 & & \\
\hline S5 & Bachelor of nursing student & Isfahan & Male & 23 & & \\
\hline S6 & Bachelor of nursing student & Najafabad & Female & 22 & & \\
\hline S7 & Bachelor of nursing student & Isfahan & Female & 23 & & \\
\hline S8 & Master of nursing student & Tehran & Female & 23 & & \\
\hline S9 & Master of nursing student & Tehran & Female & 24 & & \\
\hline
\end{tabular}

a Abbreviations: N, Nurse; CA, Clinical Administrator; I, Instructor; S, Student. 


\subsection{Data Analysis}

Data collection and analysis were done simultaneously during 16 months in 2013 and 2014. The maxqda10 software was employed for transcription and classification of codes. Conventional content analysis was used to identify categories and themes by means of the Zhang approach (Table 2) (22). Transcribed interviews were studied several times to produce an overall impression of the data, and then, important sentences were highlighted and codified into the smallest meaningful units. Meaningful units were labeled with codes and comparative analysis was performed in order to extract primary codes. During the next stage, the primary codes were classified based on differences and similarities in abstract categories and a coding scheme was shaped. The coding scheme was tested on a sample of text and then all the text was codified. All of the researchers participated in the data coding process. Continuous analysis of data began from the beginning of codification, and continued until the end of data collection. Conclusions from codified data are presented in Tables 3 and 4, and are reported in this article.

\subsection{Rigor}

To ensure trustworthiness, credibility, dependability and transferability (23), some methods were used to exactitude this research. Choosing participants from different places and various experiences increased the credibility of the research. Sample codes were given to three participants who confirmed the harmony of the codes with their statements. In addition, some sections of the transcriptions and extracted codes were sent to three experts to consider the analysis process and determine its accuracy. Finally, categories and subcategories of different interviews were combined and a complete description of factors that influence students' communication competency was obtained. For increasing the dependability of this study, prolonged sampling (16 months in duration), selection of the most suitable meaning unit, simultaneous analysis and emerging of data were conducted. The research team members discussed about the content of the study, by an open dialogue, until consensus was reached. To facilitate transferability, a clear description of the characteristics of the internship period in Iran, methods of selection and characteristics of participants, process of data collection, analysis and findings with appropriate quotations are explained in this article (20).

\subsection{Ethical Considerations}

All of the participants were informed of the study aims and methods, and were assured that participation was anonymous and voluntary. The places of interview were determined based on agreement between the hospital or university and the interviewer. Written informed consent was obtained from all participants prior to recording of their voice, and the interviewer explained the study aims.
The participants were assured that all of their information and sound files would remain confidential. The interviews were carried out only in the presence of the researcher and the interviewee and no one else. All participants signed the form of conscious satisfaction designed by the interviewer on the basis of ethical codes regarding work with human cases, and the study was approved by the Ethics Committee of the Faculty of Medical Sciences of Tarbiat Modares University (registered under 52112234 dated 22/1/2012).This study was carried out after receiving permission from all involved universities and hospitals.

\section{Results}

After analysis and codification, three main categories were extracted: organizational factors, humanistic factors and socio-cultural factors (Tables 3 and 4). The latent and major theme of this research was" patients not accepting the students", which was obvious throughout the research and in all categories. Nursing students are not accepted in clinical settings and this causes a reduction in their communication competence (Figure 1).

Table 2. The Summary of Steps of Analysis Based on the Zhang Method

\begin{tabular}{lr}
\hline Steps & Action \\
\hline Step 1 & Preparation of the Data \\
Step 2 & Definition of the Unit of Analysis \\
Step 3 & Development of Categories and a Coding Scheme \\
Step 4 & Testing of the Coding Scheme on a Sample of Text \\
\hline Step 5 & Coding All the Text \\
Step 6 & Assessment of Coding Consistency \\
Step 7 & Drawing Conclusions from the Coded Data \\
\hline Step 8 & Reporting Methods and Findings \\
\hline
\end{tabular}

Table 3. Main Categories and Subordinate Themes Obtained by Data Analysis

\begin{tabular}{lc}
\hline Categories & \multicolumn{1}{c}{ Subcategories } \\
\hline $\begin{array}{l}\text { Organization- } \\
\text { al factors }\end{array}$ & \\
\hline $\begin{array}{l}\text { The lack of student's organizational position } \\
\text { factors }\end{array}$ & Physician autocracy \\
\hline $\begin{array}{l}\text { Humanistic } \\
\text { Socio-cultural } \\
\text { factors }\end{array}$ & Student characteristics \\
\hline & Clinical nurses \\
\hline & Instructors \\
\hline
\end{tabular}


Jouzi M et al.

\begin{tabular}{l} 
Table 4. Descriptions and Participants Excerpts Corresponding to the Socio-Cultural Factors Category and its Subcategories \\
\begin{tabular}{l} 
Integrative Codes Initial Codes Meaning Units \\
\hline Social and cultural status of students
\end{tabular} \\
\hline $\begin{array}{l}\text { Patients not accepting stu- } \\
\text { dents as a caregiver }\end{array}$
\end{tabular}

Not communicat- "At the beginning, I did not introduce myself; when we introduced ourselves as a ing with students student, they did not communicate with us or behaved in a way that we did not dare to go to their room."

\begin{tabular}{|c|c|c|}
\hline & $\begin{array}{l}\text { No admission of } \\
\text { students }\end{array}$ & $\begin{array}{l}\text { "When they (patients) understand that you are a student, they think they are } \\
\text { regarded as a laboratory mouse and we want to do operations on them." }\end{array}$ \\
\hline \multicolumn{3}{|l|}{ Trust and rely on students } \\
\hline & $\begin{array}{l}\text { Use of unethical } \\
\text { methods to gain } \\
\text { the confidence of } \\
\text { the patients }\end{array}$ & $\begin{array}{l}\text { "I was afraid that they would not communicate with me. There would be better } \\
\text { communication, if I told them that I was one of the personnel." and "Some stu- } \\
\text { dents put the instructors' label on their pockets to attract the patients' attention } \\
\text { and trust. Because as soon as they realized that we were a student, they would } \\
\text { pay no attention to us." }\end{array}$ \\
\hline & Trusting students & $\begin{array}{l}\text { "Only a burn patient came and communicated with us. She was self-immolated. } \\
\text { She told us about her family problems. Nevertheless, she did not say anything to } \\
\text { the staff about herself. She had trusted us, perhaps because we were students. We } \\
\text { were there for a short time, wouldn't tell others what she had told us." }\end{array}$ \\
\hline $\begin{array}{l}\text { Family and cultural educa- } \\
\text { tion of student }\end{array}$ & Family of student & $\begin{array}{l}\text { "I had a student that was trained by me for a semester, he said hello to me during } \\
\text { that semester but did not greet me during the next semester because he had no } \\
\text { classes with me. I believe that is related to his family upbringing and what they } \\
\text { have taught him" }\end{array}$ \\
\hline \multicolumn{3}{|c|}{ Cultural differences of patients and students } \\
\hline \multirow[t]{3}{*}{$\begin{array}{l}\text { Problems in cultural percep- } \\
\text { tion }\end{array}$} & $\begin{array}{l}\text { Cultural frame- } \\
\text { work of patient }\end{array}$ & $\begin{array}{l}\text { "In some cultures, asking about the patient's sexual function results no clear } \\
\text { and correct answer; but if someone identified the culture of his patient and ask } \\
\text { him the questions according to his cultural framework, the patient would trust } \\
\text { and answer clearly." }\end{array}$ \\
\hline & $\begin{array}{l}\text { Difficulty in } \\
\text { language per- } \\
\text { ception }\end{array}$ & $\begin{array}{l}\text { "I had a patient who spoke the Arabic language... an Arabic student can com- } \\
\text { municate with him very well. But I couldn't " }\end{array}$ \\
\hline & $\begin{array}{l}\text { Differences in } \\
\text { language, gen- } \\
\text { der and age }\end{array}$ & $\begin{array}{l}\text { "During injections and giving care, in some cultures, male patients like to } \\
\text { receive care from a male nurse or vice versa. In some cultures, this is not impor- } \\
\text { tant but in some other cultures it is very important" }\end{array}$ \\
\hline
\end{tabular}

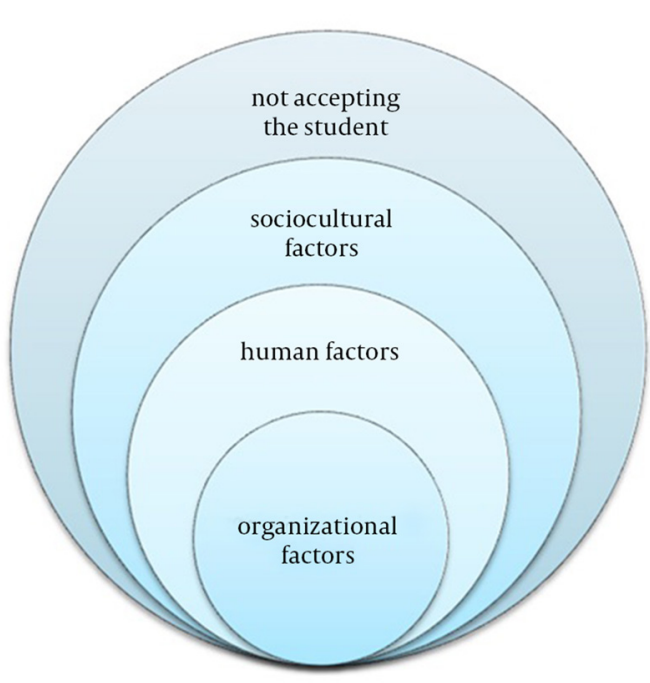

Figure 1. Factors Influencing Communicative Competence of Iranian Nursing Students

\subsection{Organizational Factors}

This research identified that organizational factors such as position of nursing students in the clinical environment and physician autocracy affected their communication competency.

\subsubsection{The Lack of Student's Organizational Position}

Lack of an adequate organizational position of nursing students in clinical environments was one of the organizational factors that the participants complained about. Duties and responsibilities of a nursing student are not clearly determined; and each member of the health care team expresses their personal opinion and this factor ruins the relationship of students with others: "Supervisors obligate us to do all work because we do not have an instructor or we are from Azad University; they think we are their servant"(S7). 


\subsubsection{Physician Autocracy}

Physician autocracy was another negative organizational factor in Iranian hospitals: "I remember that there was a patient that neither doctors nor nurses were aware of...we were talking to him and he was speaking about his disease... meanwhile, during our conversation, the physicians came and shouted at us, asking why we were talking there? He told us to leave the room. Our fault was talking with the patient"(S3).

Even instructors are affected by the physician autocracy's atmosphere and don't play their educational role: "Our managers stay away from the physicians... they never communicate with the physicians, they asked us to stay during their medical round while they go out. This also makes us stay away from physicians little by little" (S7).

\subsection{Humanistic Factors}

Humanistic factors that can affect students' communication competence include options by other students, patients, clinical nurses and instructor characteristics. The participants believed that the existence of some features in the students' personality enables or stops them to reach communication competency: "I know communicating with the patient, depends on my character... I could not communicate with my patients"(S5).

Social communication ability of students such as flexibility and having appropriate behaviors with different people can affect their communication competence: "The students were different, some had trouble with others, while some, although upset, they would adopt themselves with the condition. Some would get angry and quarreled" (S6).

Introspection and fear of communicating with patients is one of the characteristics of student that affect their ability of social communication: "I was always afraid to communicate with the patients because of my disability to do so"(S2).

\subsubsection{Patient's Behavior}

Type and severity of the patient's disease can affect the tendency of the patient to communicate with the student: "Burned patients with bad body image, had weak communication. During the week that we were at the burn hospital, we did not have any relationship with any of the patients"(S4).

Anxious and nervous behavior of critically ill patients with nursing students was another complaint of students: "I wanted to visit a patient with liver cirrhosis; I entered the room, he behaved badly. He said, "Go out, why you ask me these questions? I'm tired of you, I want to die" (S3).

\subsubsection{Clinical Nurses}

The participants believed that clinical nurses had an effective role on students' communication competency.
Most participants talked about the lack of acceptance by clinical nurses: "They would not pay any attention to us. The personnel would ignore us." (S6); "In most wards, the nurses deal with students very badly. They do not pay attention to them" (I2); "She did not teach us how to behave when dealing with patients. She just screamed at the patient and his companion"(S1).

\subsubsection{Instructor}

Many participants emphasized on the key role of the instructors as a communicative model for internship students: "At the beginning, some masters would introduce students very well and this made the staff to become familiar with students. Nevertheless, other masters would not introduce students to personnel and would not identify which patient is for which student..., therefore the students thought that they were far from the ward personnel"(N2).

Some of the instructors would not pay any attention to students' acquisition of communication competency: "When a student came to the ward, instructors just wanted them to measure blood pressure and they would not encourage them to communicate with the patients"(H1).

\subsection{Socio-Cultural Factors}

\subsubsection{Social and Cultural Status of Students}

According to the participants' experiences, the public viewpoint about nursing students is not positive. When the students are in the ward, the patients feel that they are undergoing different clinical tests and treatments for the students to learn new things and students do not care for the patients like personnel. Therefore, they do not accept students as caregivers: "When a student had come to visit a patient; she asked if he was a student? And then told him to go and tell your instructor to do the work herself"(I1).

Family features and cultural background of students is one of the factors that affect students' communication competency achievement: "There are some students that cannot communicate with others well, why? Because it depends on their family background; their families have not taught them how to communicate with others" (I3).

\subsubsection{Cultural Differences of Patients and Students}

Because of cultural gaps between students and patients and lack of cross-cultural understanding, they cannot communicate with each other. In many situations, ethical and religion principles are one of the disturbing factors: "Communicating with the patients is very hard, especially when their cultures are different, especially their language. In many situations besides gender differences, we cannot communicate with an old man at all"(S6). 


\section{Discussion}

The findings revealed that "patients do not accept students" because of organizational factors, while individual, social and cultural attributes of students, instructors, clinical nurses and patients, are the most important factors that affect the acquisition of communication competence during internship. During the internship program, because of direct contact with the higher organizational people, acceptance of the organizational position of the students by officials and nursing directors leads to less communicative problems. In the study by Beitz and Wieland (24), one of the main factors, that affected the students' view of the clinical learning environment, was the students' communication with nurses and nursing managers. Communications with physicians may be more difficult if there is a physician autocracy atmosphere (5). Physician autocracy had a negative effect on student-patient relationships in this study; and this means that, in accordance with the studies of Hanifi et al. (5) and Ardahan et al. (25), physicians still look at nurses as individuals who should implement the physicians order before meeting the needs of patients. Nursing students have deficiencies in their communication competence such as nurse-patient communication during medication administration (26). The students are concerned about rejection by patients and their families just because of being a student (27). A number of the students participating in the current research stated that they were afraid of communicating with patients. Fear of dealing with the patient, lack of confidence and emotional distress are the main known causes that make the students become distant from the patients (28), conversely, knowing the student's personality with potentials and limitations is essential for a facilitative relationship (11) and providing care for patients without prejudice toward different patients is one of the most important items of professional values (29). Clinical nurses, as future coworkers, have a vital role in training nursing students (30). In many educational hospitals of Iran, the instructor doesn't have a stable presence during the internship period, so the student works directly with clinical nurses. Therefore, some nurses who are interested in training will teach the students informally, while they are also the students' coworkers or supervisors. Students believe that clinical nurses are a procedure model; a qualified, powerful and attractive model (30). Nursing students are concerned about mistakes made due to insufficient knowledge and skills (31). Thus, positive relationships between students and experts, and interested and kind ward staff, can reduce the stress of students in the clinical environments (32) and are critical for them because the student's need for support, respect and acceptance from more experienced colleagues is of major importance to them (33) and this sense of belonging can influence their communication competency acquisition. The results of this research, similar to the study of Atack et al. (34) showed that even simple suggestions such as offering to sit or invitation to the break room, create a sense of admiring and belonging for the nursing student. Many participating students claimed that in many situations they were ignored or met with indifference. These findings confirmed the results of studies about the fact that students are not admitted as legal members of the team; thus they are neglected, isolated or abandoned. These researchers have emphasized on the importance of the sense of belonging for nursing students as part of the health care team $(28,35)$. In the nursing education system of Iran, clinical instructors are the main people responsible for training nursing students during their internship. One of the most important criteria for effective clinical instructors is their ability to establish an interpersonal communication competence (36). If the instructor does not establish a good relationship with the members of the clinical team, she/he cannot cooperate with them (37). The personal attributes of the instructor not only directly affect training, nursing or interpersonal relationships, but indirectly influences all of them (38), thus having a friendly and supportive behavior is very important for the clinical educator (31). Nursing instructors could have a good relationship with their students when they respect them, have realistic expectations, are honest and truthful, encourage them, and help them in clinical environments (28). According to the research participants, instructors who have these features had a positive effect on the students' communication competency acquisition. Unfortunately, the nursing profession in Iran does not have a positive reputation amongst the pubic $(5,39)$, and this negative view could affect the nursing students. The relationship between students and patients seems to be largely determined by their preconceptions and stereotypes about one another and personal qualities of both of them (11). In most cases included in this study, the lack of students' acceptance by patients and their families was mentioned and consistent with some previous study results; patients did not take the opportunity to contribute to student learning (11). Finally, based on the results of our research, it seems that the main factor that affects the students' communication competence is the lack of students' acceptance as a caregiver by health care providers, instructors, patients and their families in clinical settings (Figure 1). By considering the purpose of the internship period and the fact that effective teaching of communication skills is critical for preparing future nurses and delivering safe care (40), it is recommended for authorities to design a comprehensive system for training nursing instructors with appropriate communication skills, and to improve the organizational and social position of the nursing students. We suggest that in order to develop this competency, firstly, health authorities must prepare the environment for accepting students and defining their clinical situation as care providers in hospitals. Because of the sampling strategy of this study and focus on an Iranian population, when generalizing the study findings, cultural differences must be 
considered. Although heterogeneous samples have yielded wide findings, the present results can be considered to have a wider relevance to similar clinical contexts. The focus of this study was to determine the effect of individuals, who are present in clinical settings, on the acquisition of communication competency in students.

\section{Acknowledgements}

The research team acknowledges all of the participants in this research and the vice-chancellors of research of Tarbiat Modares University for their financial support.

\section{Authors' Contributions}

Study design: Mina Jouzi, Zohreh Vanaki and Easa Mohammadi. Data collection: Mina Jouzi. Data analysis and interpretation of data: Mina Jouzi, Zohreh Vanaki and Easa Mohammadi. Drafting of the manuscript: Mina Jouzi and Zohreh Vanaki. Critical revision of the manuscript for important intellectual content: Mina Jouzi and Zohreh Vanaki. Study Supervision: Zohreh Vanaki and Easa Mohammadi.

\section{Funding/Support}

This study was part of a PhD dissertation of the first author, approved and supported by the Tarbiat Modares University, Tehran, IR Iran [number 52/127821dated 8/3/91].

\section{References}

1. Yekta ZP, Ramezani Badr F, Khatooni A. Nursing studens' concerns about their clinical competencies and level of attachment to them. Nurs Res. 2007;1(3):7-14.

2. Dolan G. Assessing student nurse clinical competency: will we ever get it right? J Clin Nurs. 2003;12(1):132-41.

3. Sportsman S. Competency education and validation in the United States: what should nurses know? Nurs Forum. 2010;45(3):1409.

4. Vahidi RG, Daneshkhah N, Araks M, Koshavar H, Mohammadpour A. Nursing students' and instructors' viewpoints regarding professional abilities of students in internship program at Tabriz University of Medical Science. Iran J Med Educ. 2006;6(2):107-13.

5. Hanifi N, Parvizy S, Joolaee S. The Miracle of Communication as a Global Issue in Clinical Learning Motivation of Nursing Students. Procedia Soc Behav Sci. 2012;47:1775-9.

6. Kettunen T, Poskiparta M, Gerlander M. Nurse-patient power relationship: preliminary evidence of patients' power messages. Patient Educ Couns. 2002;47(2):101-13.

7. Gough J, Johnson L, Waldron S, Tyler P, Donath S. Clinical communication: Innovative education for graduate nurses in paediatrics. Nurse Educ Pract. 2009;9(3):209-14.

8. Chant S, Jenkinson T, Randle J, Russell G. Communication skills: some problems in nursing education and practice. J Clin Nurs. 2002;11(1):12-21.

9. Mullan BA, Kothe EJ. Evaluating a nursing communication skills training course: The relationships between self-rated ability, satisfaction, and actual performance. Nurse Educ Pract. 2010;10(6):374-8.

10. O'Malley Floyd B, Kretschmann S, Young H. Facilitating role transition for new graduate RNs in a semi-rural healthcare setting.J Nurses Staff Dev. 2005;21(6):284-90.

11. Suikkala A, Leino-Kilpi H. Nursing student-patient relationship: experiences of students and patients. Nurse Educ Today. 2005;25(5):344-54.

12. Satu KU, Leena S, Mikko S, Riitta S, Helena LK. Competence areas of nursing students in Europe. Nurse Educ Today. 2013;33(6):62532.

13. Shipman D, Roa M, Hooten J, Wang ZJ. Using the analytic rubric as an evaluation tool in nursing education: the positive and the negative. Nurse Educ Today. 2012;32(3):246-9.

14. Rosenberg S, Gallo-Silver L. Therapeutic communication skills and student nurses in the clinical setting. Teach and Learn in Nurs. 2011;6(1):2-8.

15. McGilton K, Irwin-Robinson H, Boscart V, Spanjevic L. Communication enhancement: nurse and patient satisfaction outcomes in a complex continuing care facility. J Adv Nurs. 2006;54(1):35-44.

16. Suikkala A, Leino-Kilpi H. Nursing student-patient relationship: a review of the literature from 1984 to 1998. J Adv Nurs. 2001;33(1):42-50.

17. Fallowfield L, Saul J, Gilligan B. Teaching senior nurses how to teach communication skills in oncology. Cancer Nurs. 2001;24(3):185-91.

18. Jaffari-Golestan N, Vanaki Z, Memarian R. Organizing "nursing mentors committee": an effective strategy for improving novice nurses' clinical competency. Iran J Med Educ. 2008;7(2):236-7.

19. Khomeiran RT, Yekta ZP, Kiger AM, Ahmadi F. Professional competence: factors described by nurses as influencing their development. Int Nurs Rev. 2006;53(1):66-72.

20. Polit D, Beck C. Essential of nursing research:method, appraisal and utilization. 7th edPhiladelphia: Lippincott Williams \& Wilkins; 2010.

21. Streubert SH, Carpenter RD. Qualitative Research in Nursing, Advancing the Humanistic Imperative.Philadelphia: Lippincott-Williams \&Wilkins; 2007.

22. Zhang Y, Wildemuth BM. Qualitative analysis of content Applications of social research methods to questions in information and library science.Westport, CT: Libraries Unlimited; 2009.

23. Graneheim UH, Lundman B. Qualitative content analysis in nursing research: concepts, procedures and measures to achieve trustworthiness. Nurse Educ Today. 2004;24(2):105-12.

24. Beitz JM, Wieland D. Analyzing the teaching effectiveness of clinical nursing faculty of full- and part-time generic BSN, LPN-BSN, and RN-BSN nursing students. J Prof Nurs. 2005;21(1):32-45.

25. Ardahan M, Akcasu B, Engin E. Professional collaboration in students of Medicine Faculty and School of Nursing. Nurse Educ Today. 2010;30(4):350-4.

26. Ghamari-Zare Z, Purfarzad Z, Adib-Hajbaghery M. Medication Management Skills of Nursing Students: Comparing the Students and Their Instructors' Evaluation in two Universities. Nurs Midwifery Stud. 2013;1(3).

27. Gilmartin J. Teachers' understanding of facilitation styles with student nurses. Int J Nurs Stud. 2001;38(4):481-8.

28. Grilo AM, Santos MC, Rita JS, Gomes AI. Assessment of nursing students and nurses' orientation towards patient-centeredness. Nurse Educ Today. 2014;34(1):35-9.

29. Parvan K,Zamanzadeh V, Hosseini FA. Assessment of Professional Values Among Iranian Nursing Students Graduating in Universities With Different Norms of Educational Services. Thrita J Med Sci. 2012;1(2):37-43.

30. Jones SH. Nursing students' perceptions of working with staff nurses. Montana state university. 2010.

31. Heshmati F, Vanaki Z. Effective clinical instructor: A qualitative study. Iran Nurs Res. 2009;4(12,13):39-53.

32. Gray MA, Smith LN. The qualities of an effective mentor from the student nurse's perspective: findings from a longitudinal qualitative study. JAdv Nurs. 2000;32(6):1542-9.

33. Andrews GJ, Brodie DA, Andrews JP, Hillan E, Gail Thomas B, Wong J, et al. Professional roles and communications in clinical placements: a qualitative study of nursing students' perceptions and some models for practice. Int J Nurs Stud. 2006;43(7):861-74.

34. Atack L, Comacu M, Kenny R, LaBelle N, Miller D. Student and staff relationships in a clinical practice model: impact on learning. $J$ Nurs Educ. 2000;39(9):387-92.

35. Levett-Jones T, Lathlean J. Belongingness: a prerequisite for nursing students' clinical learning. Nurse Educ Pract. 2008;8(2):103-11.

36. Tang FI, Chou SM, Chiang HH. Students' perceptions of effective and ineffective clinical instructors. J Nurs Educ. 2005;44(4):187-92.

37. Saarikoski M, Warne T, Kaila P, Leino-Kilpi H. The role of the nurse 


\section{Jouzi M et al.}

teacher in clinical practice: an empirical study of Finnish student nurse experiences. Nurse Educ Today. 2009;29(6):595-600.

38. Salminen LK, Melender HL, Leino-Kilpi H. The Competence of Student Nurse Teachers. Int J Nurs Educ Scholarsh. 2009;6(1).

39. Nasrabadi AN, Lipson JG, Emami A. Professional nursing in Iran: an overview of its historical and sociocultural framework. J Prof Nurs. 2004;20(6):396-402.

40. O'Shea ER, Pagano M, Campbell SH, Caso G. A descriptive analysis of nursing student communication behaviors. Clin Simul Nurs. 2013;9(1):e5-e12. 